\title{
SISTEM INFORMASI MANAJEMEN ADMINISTRASI KEUANGAN PANTI ASUHAN BERBASIS WEBSITE
}

\author{
Akhmad Syukron ${ }^{1}$, Purwaningsih ${ }^{2}$ \\ 1 Universitas Bina Sarana Informatika \\ e-mail: akhmad.khy@bsi.ac.id \\ ${ }^{2}$ Universitas Bina Sarana Informatika \\ e-mail: purwanin2411@bsi.ac.id
}

\begin{abstract}
Abstrak
Panti asuhan merupakan salah satu lembaga non-profit atau lembaga sosial yang memiliki wewenang dan tanggung jawab terhadap anak-anak penghuni panti untuk memberikan pelayanan kesejahteraan sosial. Pengelola panti harus mampu memanajemen panti asuhan dengan baik,, salah satunya adalah dalam hal manajemen keuangan. Saat ini panti asuhan hafara dalam mengelola keuangan masih menggunakan cara konvensional yaitu dengan mencatat transaksi keuangan menggunakan buku kas. Dengan cara konvensional masih terdapat beberapa kelemahan atau resiko seperti resiko hilangnya data, rusaknya buku kas, salah perhitungan dan juga kesulitan dalam membuat laporan keuangan. Oleh karena itu untuk meminimalisir resiko yang ada dan juga memudahkan dalam manajemen keuangan panti diperlukan sebuah sistem informasi terkomputerisasi. Selain itu juga dapat memudahkan pengelola panti dan juga donatur dalam memantau dan evaluasi keuangan panti yang dapat diakses dengan cepat dan dimana saja. Tujuan dari penelitian ini adalah untuk membuat sistem informasi administrasi keuangan panti asuhan berbasis website dengan menggunakan metode pengembangan perangkat lunak waterfall.
\end{abstract}

Kata Kunci: Sistem Informasi, Administrasi Keuangan, Panti Asuhan, Website

\begin{abstract}
The orphanage is a non-profit institution or social institution that has the authority and responsibility for the children of the orphans to provide social welfare services. The management of the orphanage must be able to manage the orphanage well, one of which is in terms of financial management. Currently hafara orphanage in managing finances is still using the conventional way by recording financial transactions using cash books. In the conventional way there are still some weaknesses or risks such as the risk of data loss, damage to the cash book, miscalculations and also difficulties in making financial statements. Therefore, to minimize the risks that exist and also facilitate financial management in the institution, a computerized information system is needed. It also can facilitate the management of the institution and also donors in monitoring and evaluating financial institutions that can be accessed quickly and anywhere. The purpose of this study is to create a financial administration information system for website-based orphanages using the waterfall software development method.
\end{abstract}

Keywords: Information Systems, Financial Administration, Orphanages, Website 


\section{Pendahuluan}

Peran teknologi informasi di era digitalisasi seperti sekarang ini sangatlah penting untuk mendukung segala bentuk kegiatan pada suatu instansi, baik pada instansi pemerintah, perusahaan, lembaga kemasyarakatan dan juga perorangan. Dengan penggunaan sistem informasi yang terkomputerisasi, dapat membuat orang menjadi lebih mudah dalam mengelola data dan informasi yang dibutuhkan.

Panti asuhan merupakan suatu lembaga sosial yang memiliki wewenang dan tanggung jawab dalam memberikan pelayanan kesejahteraan sosial bagi anak terlantar. Dalam pelaksanaannya, panti asuhan harus mengacu pada standar nasional pengasuhan anak untuk lembaga kesejahteraan sosial anak. Termasuk juga standar kelembagaan yang terdiri dari visi dan misi, perijinan, peran dinas sosial, pendirian dan akreditasi lembaga serta fasilitas (Minarni, Yulianti, \& Warman, 2016)

Panti asuhan hafara merupakan salah satu lembaga sosial masyarakat yang memiliki tanggung jawab menjaga dan merawat warga panti juga bertanggung jawab kepada masyarakat umum khususnya kepada donatur panti yang telah memberikan sumbangan untuk keberlangsungan panti dalam hal transparansi pengelolaan keuangan panti asuhan. Saat ini pengelolaan keuangan pada panti asuhan hafara masih dilakukan dengan cara mencatat pada buku besar. Dengan menggunakan buku catatan keuangan masih terjadi resiko ketidakakuratan data, kerangkapan data dan juga mengalami kesulitan dalam memberikan laporan keuangan kepada para donatur.

Oleh karena itu untuk mengatasi permasalahan yang terjadi diperlukan sebuah sistem informasi yang dapat digunakan sebagai sarana pendukung kegiatan panti khususnya pada bidang pengelolaan keuangan panti. Sehingga nantinya dapat terwujud sistem informasi manajemen keuangan yang akurat dan akuntable. Selain itu dapat terwujud prinsip tranparansi anggaran dan juga dapat memudahkan para donatur dan masyarakat umum untuk mengakses informasi pengelolaan keuangan secara cepat, tepat, akuran dan juga efisien.

Tujuan dari penelitian ini yaitu untuk membuat suatu sistem informasi yang berbasis website untuk manajemen administrasi keuangan panti asuhan yang efektif dan efisien. Beberapa penelitian sebelumnya tentang pemanfaatan sistem informasi untuk pengelolaan panti asuhan telah dilakukan.

Beberapa peneletian terdahulu yang relevan antara lain. Purnomo \& Maknunah (2018) dalam penelitiannya membuat sistem informasi pengelolaan data keuangan berbasis web, untuk memudahkan pimpinan dalam pengaksesan data.

Wijayanto, Riyantomo, \& Nugroho Eko Budiyanto (2018) melakukan penelitian tentang rancang bangun sistem informasi administrasi keuangan berbasis web pada SMK NU Ungaran yang bertujuan untuk membangun sistem informasi administrasi keuangan berbasis website untuk memberikan informasi keuangan bagi peserta didik dan juga mengatasi masalah dalam hal penagihan berkala.

Sistem informasi Manajemen merupakan sistem informasi terkomputerisasi yang bekerja karena adanya interaksi manusia dan komputer (Mulyani, 2016). Sistem informasi manajemen akan menghasilkan output berupa informasi yang dapat dijadikan sebagai pertimbangan atau alat untuk mengambil keputusan. Informasi yang dihasilkan oleh sistem informasi manajemen adalah informasi yang mengambarkan halhal masa lalu saat ini, dan apa yang akan terjadi di masa mendatang (Mulyani, 2016). Tujuan dari sistem informasi manajemen keuangan yaitu untuk peningkatan kualitas laporan keuangan yang tepat waktu, akurat serta dapat dipertanggungjawabkan. Selain itu juga untuk mendukung efisiensi, efektivitas dan kelancaran penyusunan laporan keuangan.

Adminitrasi merupakan suatu kegiatan penyusunan serta pencatatan data dan informasi yang dilakukan secara sistematis yang bertujuan untuk menyediakan keterangan serta kemudahan dalam memperoleh informasi secara menyeluruh dalam hubungan antara satu sama lain (Sulasmoro \& Aprianti, 2016).

Administrasi keuangan adalah Suatu proses pengelolaan keuangan yang dilakukan oleh suatu organisasi sektor privat maupun organisasi publik. Setiap organisasi pasti memiliki sumber keuangan dan juga alokasinya. Sehingga administrasi keuangan menjadi salah satu hal yang mutlak dalam 
sebuah organisasi (Sumardiono, 2018). Dengan adanya sistem administrasi keuangan yang baik dapat menjadi penunjang kemajuan organisasi serta dapat menjadi pendorong terbentuknya sistem keuangan yang lebih baik (Saleh, 2017).

Manfaat Administrasi Keuangan

1. Agar pencatatan penerimaan dan pengeluaran suatu organisasi menjadi lebih teratur.

2. Penggunaan dana organisasi menjadi lebih terkendali, lebih terkoordinasi, dan lebih bermanfaat.

3. Dapat meminimalisir Potensi terjadinya kekeliruan pembuatan laporan keuangan.

Pada pelaksanaannya administrasi keuangan terdiri dari beberapa komponen seperti perencanaan, penganggaran, pengelolaan, pencarian, penyimpanan, pengendalian dan juga pemeriksaan keuangan.

\section{Metode Penelitian}

Metode penelitian yang digunakan pada penelitian ini yaitu metode pengembangan perangkat lunak waterfall. Metode ini adalah model pengembangan perangkat lunak yang sistematik dan sekuensial (Sasmito, 2017). Metode waterfall terdiri dari 5 tahapan yaitu Requirements definition, System and software design, Implementation and unit testing, Integration and system testing, Operation and maintenance (Sommerville, 2011).

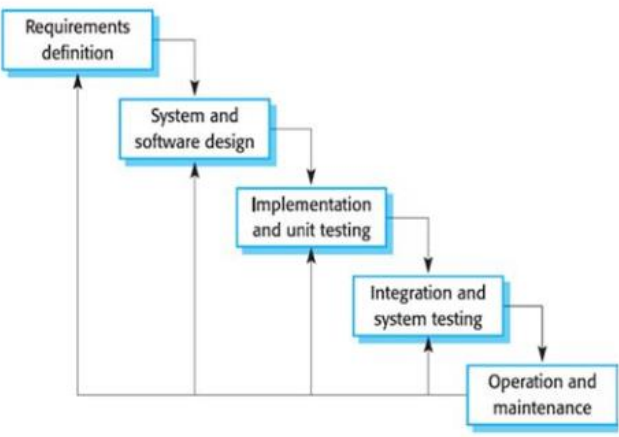

Gambar 1. Metode waterfall

Sumber : Sommerville(2011)

a. Requirements definition
Pada tahapan ini dilakukan pengumpulan kebutuhan secara intensif yang didefinisakn secara rinci agar dapat memahami spesifikasi

kebutuhan perangkat lunak sesuai kebutuhan user.

b. System and software design

Tahapan ini merupakan tahapan perancangan sistem yang mengalokasikan kebutuhan sistem seperti hardware maupun software dengan membentuk arsitektur sistem secara menyeluruh yang melibatkan identifikasi dan penggambaran abstraksi sistem dasar software dan hubungannya.

c. Implementation and unit testing

Pada tahapan ini, rancangan perangkat lunak direalisasikan menjadi rangkaian program atau unit program dengan Pengujian yang melibatkan verifikasi bahwa setiap unit telah memenuhi spesifikasinya.

d. Integration and system testing

Pada tahapan ini, unit program digabung dan dilakukan pengujian sebagai sebuah sistem yang lengkap yang bertujuan untuk memastikan apakah sistem yang dibuat sudah sesuai dengan kebutuhan perangkat lunak yang diinginkan atau tidak. Setelah dilakukan pengujian, perangkat lunak dapat diserahkan ke customer.

e. Operation and maintenance

Pada bagian Maintenance melibatkan perbaikan kesalahan-kesalahan yang tidak ditemukan pada tahapan sebelumnya, meningkatkan implementasi dari unit sistem, dan juga meningkatkan layanan sistem sebagai kebutuhan baru.

\section{Hasil dan Pembahasan \\ 3.1. Analisa Kebutuhan}

Pada tahapan analisa kebutuhan dilakukan pengumpulan data analisa sistem berjalan yang digunakan saat ini untuk identifikasi agar dapat mengetahui kebutuhan sitsem yang akan dibangun. Oleh karena itu dilakukan analisa kebutuhan sistem dan analisa kebutuhan pengguna agar dapat menyelesaikan permasalahan yang dihadapi. Berdasarkan data yang telah dilakukan maka dapat digambarkan analisa sistem berjalan administrasi keuangan panti asuhan adalah sebagai berikut. 


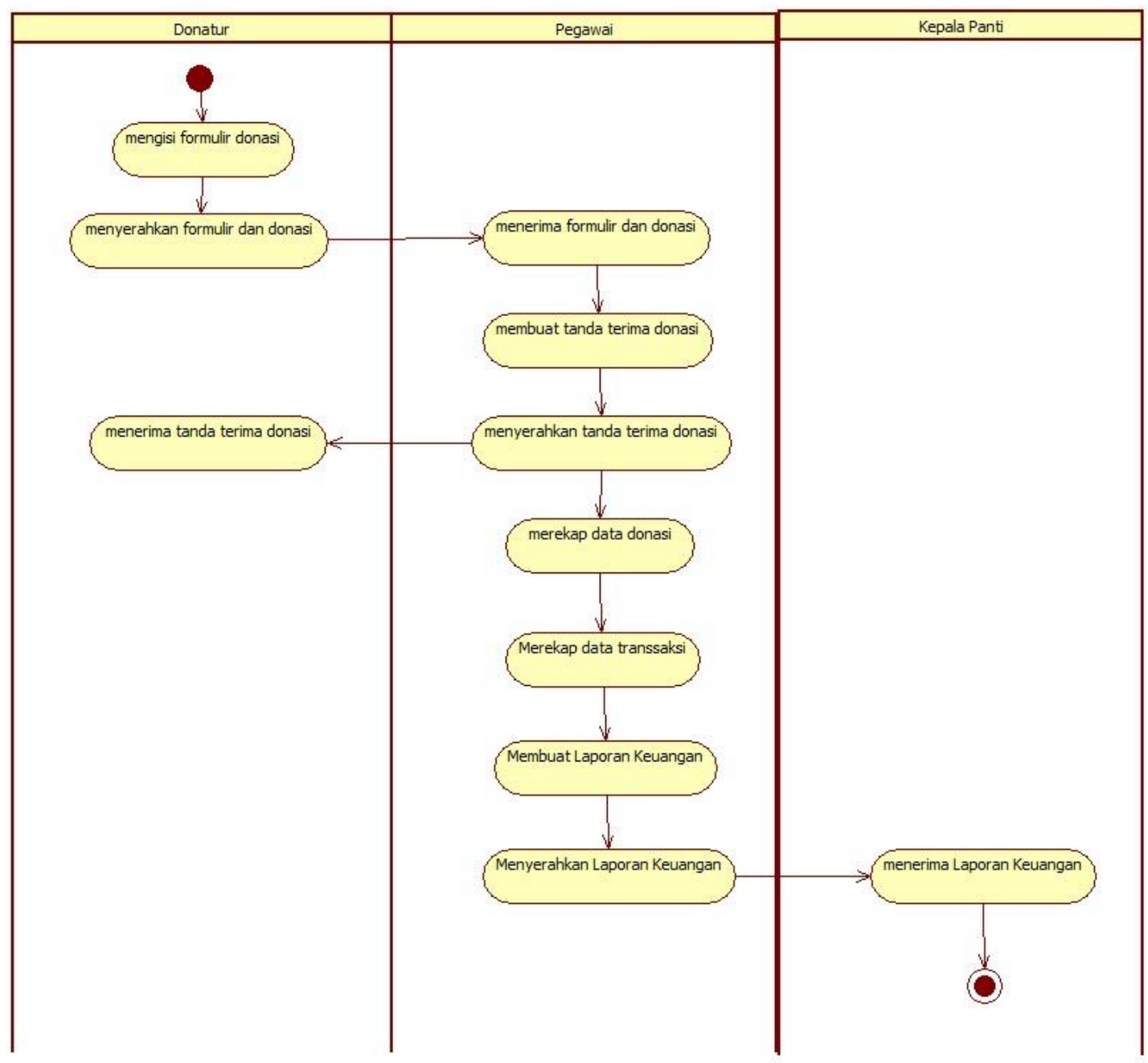

Gambar 2. Activity Diagram Sistem Berjalan

Sumber : Hasil Penelitian (2020)

Berdasarkan hasil pertemuan dengan pengguna tentang rencana kebutuhan dan identifikasi tujuan dari sistem informasi yang dibuat untuk mengatasi permasalahan yang ada, maka dapat dijelaskan sebagai berikut. 1. Analisa Kebutuhan pengguna

Pengguna sistem ini dibagi menjadi 2 yaitu pengguna biasa untuk donatur, dan pengguna sebagai administrator sistem yang diperuntukan oleh pengelola panti asuhan.

2. Analisa Kebutuhan sistem

Secara kegunaan, sistem yang dibuat untuk pengguna biasa (donatur) agar donatur dapat lebih mudah mendapatkan informasi keuangan panti dan juga bisa mengetahui dan monitoring donasi yang ada dan yang telah diberikan untuk

\begin{abstract}
keperluan sebagaimana mestinya sebagai bentuk transparansi penggunaan anggaran. Sedangkan untuk administrator berfungsi sebagai pengelola sistem keuangan panti, mulai dari mengelola data donatur, data pegawai panti, mengelola donasi masuk dan pengeluaran, serta juga untuk membuat laporan keuangan panti yang akurat dan akuntabel.
\end{abstract}

\subsection{Desain Sistem}

Pada tahapan ini, dilakukan perancangan sistem dengan membuat prototipe sistem yang akan dibuat yang merupakan representasi visual desain dan pola kerja yang ditujukan kepada pengguna. Untuk mereprentasikannya dibuat diagram ERD dan LRS sebagai gambaran 
rancangan database, dan juga diagram usecase untuk menggambarkan fungsionalitas sistem serta tampilan antarmuka sistem. Adapun bentuk rancangannya adalah sebagai berikut.

1. Usecase diagram sistem usulan

Usecase Diagram menggambarkan fungsionalitas sistem secara umum yang telah dirancang. Usecase diagram terdiri dari 2 aktor utama yaitu donatur dan pegawai panti. Donatur memiliki usecase donasi, mengelola profil, serta mengecek laporan. Sedangkan untuk pegawai memiliki usecase mengelola donatur, mengelola donasi, mengelola laporan dan juga mengelola pegawai seperti yang tergambar pada diagram usecase dibawah ini.

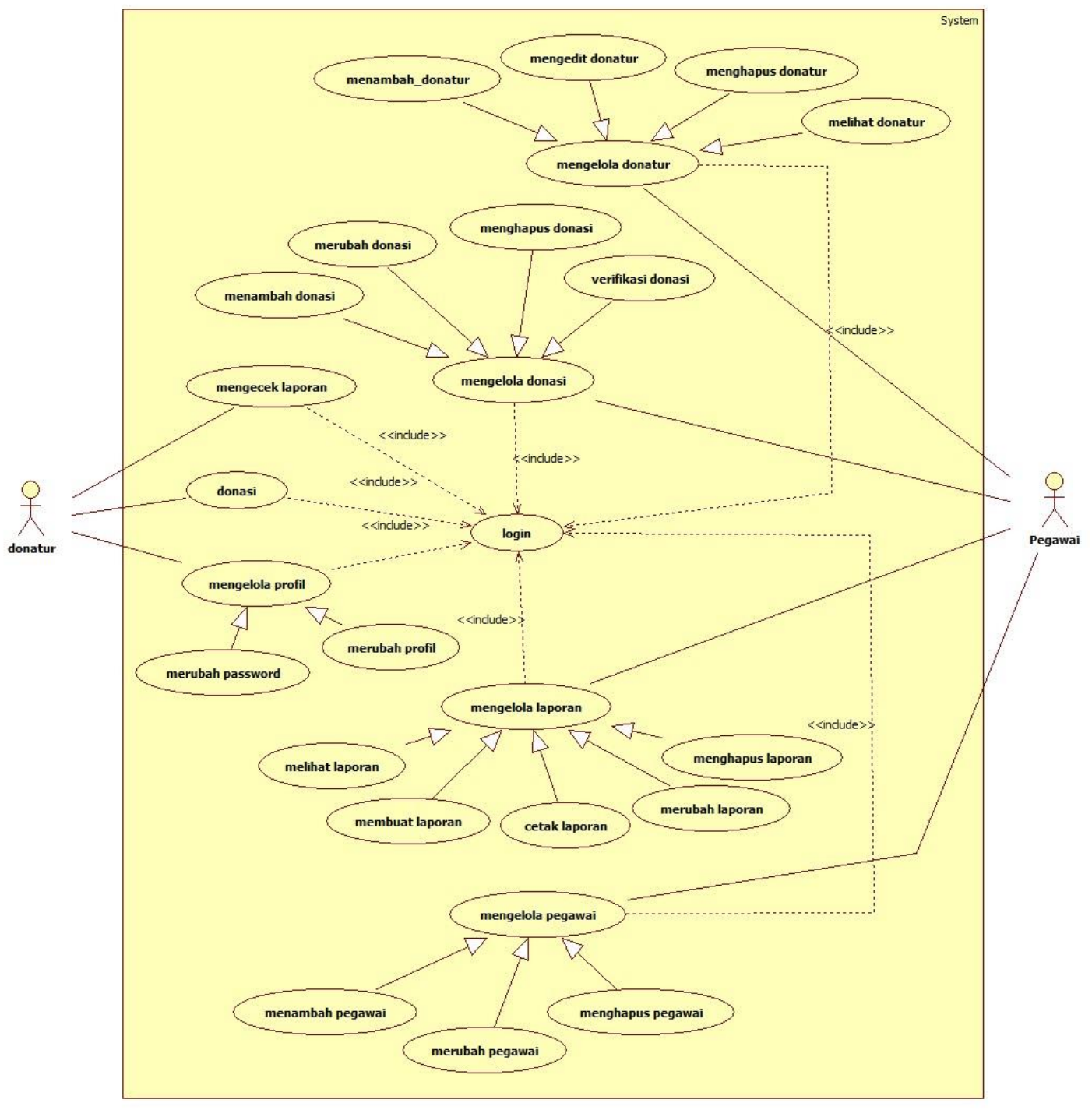

Gambar 3. Use case diagram Sistem usulan Sumber: Hasil Penelitian (2020)

2. Entity Relationship Diagram (ERD)

ERD merupakan sebuah penggambaran grafis yang menggambarkan basis data yang akan dibangun secara konseptual (Andriani \& Purnama, Eka, 2018). Berikut ERD sistem usulan. 


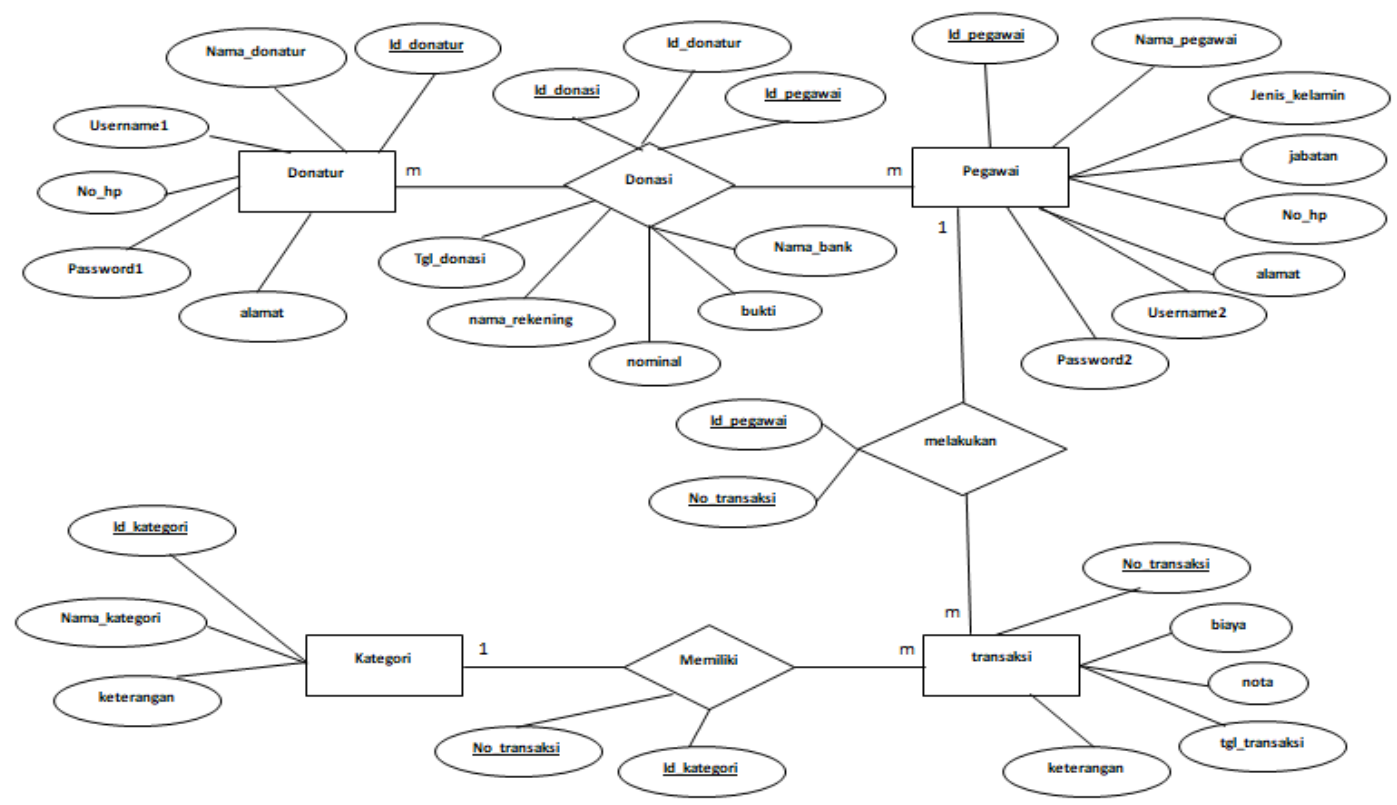

Gambar 4.

ERD Sistem administrasi Keuangan Panti

Sumber : Hasil Penelitian 2020

\section{Logical Relational Structure(LRS)}

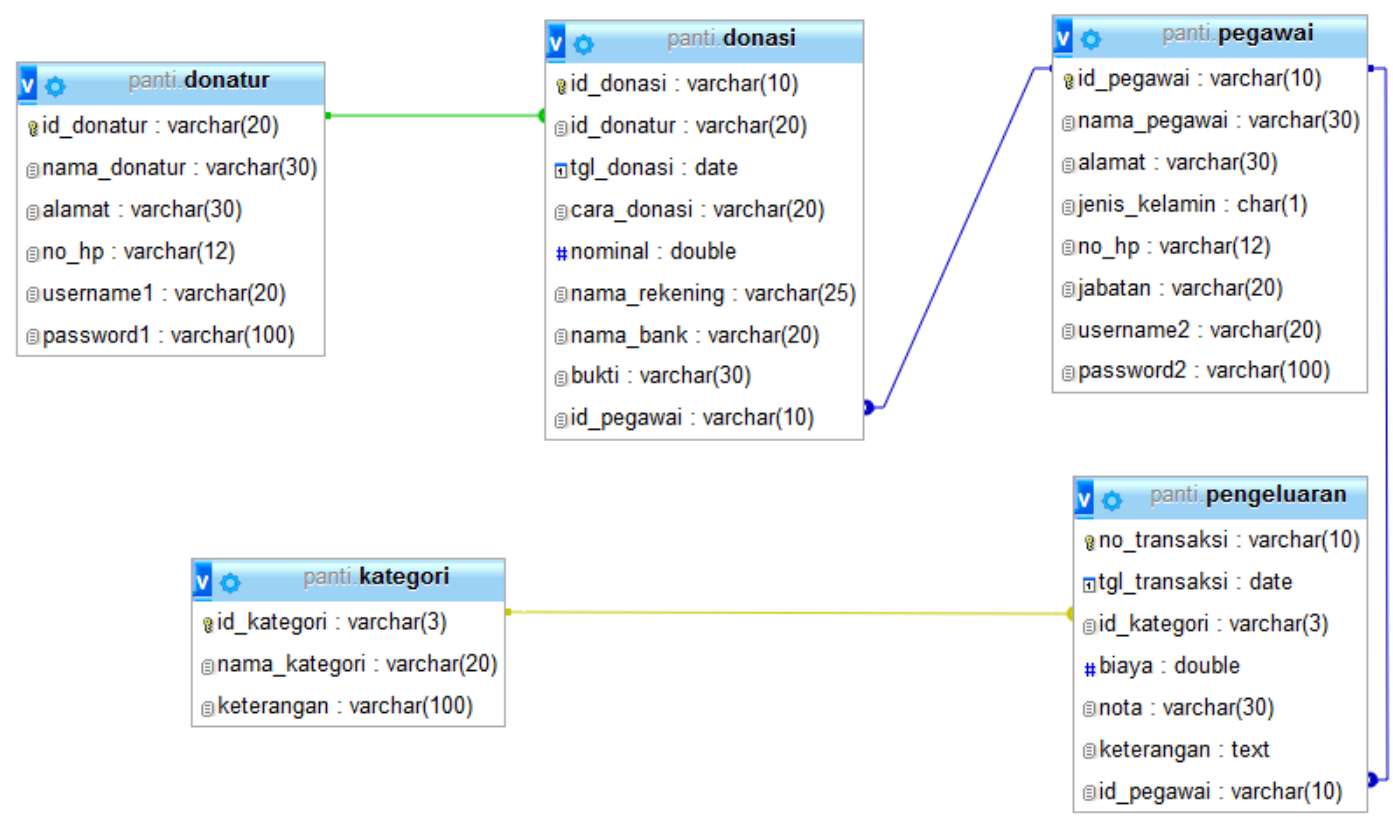

Gambar 5.

LRS Sistem administrasi Keuangan Panti

Sumber : Hasil Penelitian 2020

\subsection{Implementation And Unit Testing}

Pada tahapan ini rancangan perangkat lunak yang telah dibuat sebelumnya diimplementasikan menjadi rangkaian unit program. Selanjutnya semua unit program yang dibuat dilakukan pengujian terlebih dahulu dengan mengverifikasi apakah semua unit program sudah sesuai dengan spesifikasi yang diinginkan. Berikut adalah implementasi tampilan antarmuka sistem yang dibuat. 
a. Tampilan halaman Dashboard Admin Halaman dashboard admin adalah halaman utama dari administrator yang menampilkan data jumlah saldo, data donatur, data donasi bulanan dan juga grafik donasi.

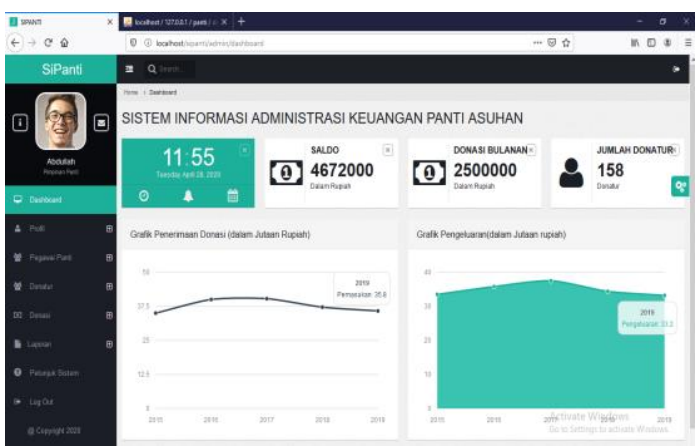

Gambar 6. Halaman Dashboard Utama Admin

Sumber : Hasil Penelitian 2020

b. Tampilan Halaman Daftar Donasi

Halaman ini menampilkan daftar rincian donasi dari para donatur untuk panti asuhan. Data bersumber dari inputan donatur dan juga dari admin untuk donasi yang dilakukan secara langsung. Admin juga dapat melakukan update data dan menghapus data donasi.

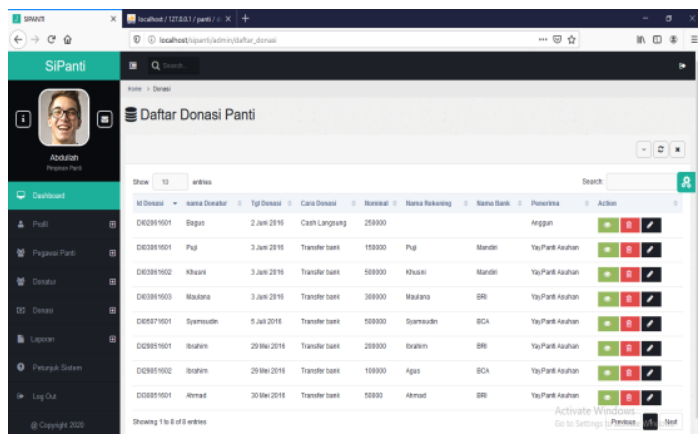

Gambar 7. Halaman daftar donasi panti Sumber : Hasil Penelitian 2020

c. Tampilan Halaman Donatur

Halaman ini untuk menampilkan data para donatur panti yang sudah terdaftar di sistem. Admin dapat menambahkan data baru, mengubah data dan juga menghapus data donatur panti.

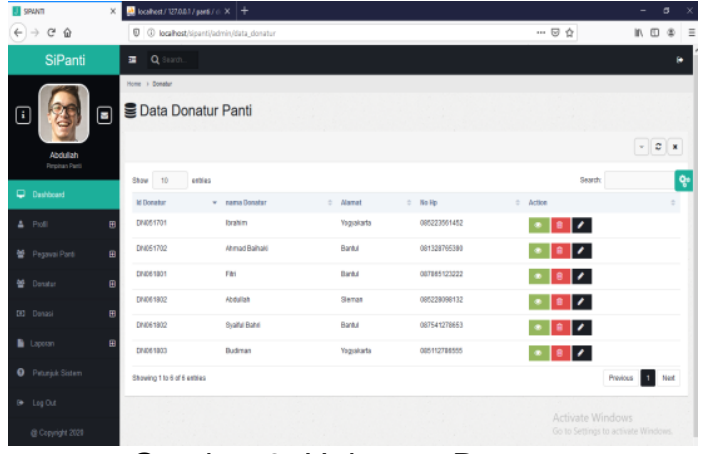

Gambar 8. Halaman Donatur

Sumber : Hasil Penelitian 2020

d. Tampilan Halaman Laporan Keuangan Panti

Halaman ini merupakan halaman untuk menampilkan laporan keuangan panti dalam kurun waktu satu bulan. Halaman ini juga tersedia di tampilan donatur. Sehingga donatur juga mendapat informasi laporan keuangan. Admin dan donatur dapat mencetak laporan keuangan.

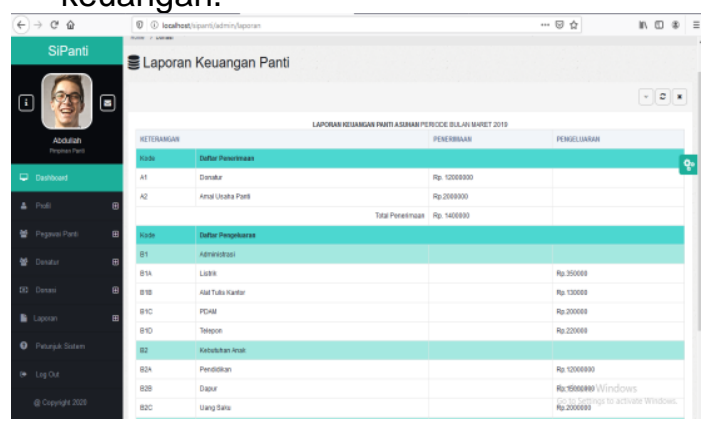

Gambar 9. Halaman laporan Keuangan Sumber : Hasil Penelitian 2020

\section{4. integration and system testing}

Pada tahapan ini unit program yang telah dibuat dan juga dilakukan pengujian digabung menjadi sebuah sistem yang lengkap. Setelah menjadi satu kesatuan program utuh Pengujian dilakukan dengan cara mencoba fungsi dari masing-masing unit program dari halaman user dan juga administrator. Dari hasil pengujian yang telah dilakukan, semua fungsi dari seluruh unit program sudah sesuai dengan yang diharapkan.

\subsection{Operation and maintenance \\ Pada tahapan ini dilakukan} maintenance pada bagian-bagian program yang terdapat kesalahan yang tidak ditemukan sebelumnya setelah dilakukan pengujian pada unit program yang dllakukan secara online pada hosting maupun offline. 


\section{Kesimpulan}

Sistem informasi manajemen administrasi keuangan panti asuhan berbasis website ini dapat memberikan kemudahan bagi pengelola panti dan juga para donatur untuk mengelola data keuangan dan juga kemudahan dalam mendapatkan informasi. Penggunaan sistem ini dapat lebih akurat dalam penghitungan keuangan dan juga efektif serta efisien dibandingkan dengan cara konvensional yang dicatat menggunakan media buku.

Untuk memudahkan dalam membaca laporan keuangan, kedepannya dapat dikembangakn dengan menambahkan fitur tampilan data berupa grafik laporan keuangan. Yang mana grafik tersebut nantinya dapat menampilkan data secara periodik baik harian, mingguan, bulanan maupun tahunan.

\section{Referensi}

Andriani, A., \& Purnama, Eka, B. (2018). Desain Database dengan ERD dan LRS. Yogyakarta: Teknosain.

Minarni, Yulianti, E., \& Warman, I. (2016). Perancangan Sistem Informasi Panti Asuhan di Kota Padang. Momentum, 18(2), 35-41.

Mulyani, S. (2016). Analisis dan Perancangan Sistem Informasi Manajemen Keuangan Daerah Notasi Pemodelan: Unified Modeling Language(UML). Bandung: Abdi Persada.

Purnomo, H., \& Maknunah, J. (2018). Sistem Informasi Pengolahan Data Keuangan Berbasis Web. JIMP, 3(3), 44-49.

Saleh, T. (2017). Sistem informasi Administrasi Keuangan MA Ibrahimy Secang Kalipuro Banyuwangi. Aitech, 3(1), 51-58.

Sasmito, G. (2017). Penerapan Metode Waterfall pada desain sistem informasi geografis industri Kabupaten Tegal. JPIT, 2(1), 6-12.

Sommerville, I. (2011). Software Engineering (Rekayasa Perangkat Lunak. Jakarta: Erlangga.

Sulasmoro, A. H., \& Aprianti, P. (2016).
Sistem Informasi Pengelolaan

Administrasi Keuangan Pada SD Muhammadiyah. Smart Comp, 5(2), 149-153.

Sumardiono, W. (2018). Pedoman Umum Organisasi dan Administrasi Rukun Warga Rukun Tetangga. Yogyakarta: Deepublish.

Wijayanto, D. P., Riyantomo, A., \& Nugroho Eko Budiyanto. (2018). Rancang bangun Sistem informasi Administrasi Keuangan Berbasis Web Pada SMK NU Ungaran. Momentum, 14(2), 8391. 